\title{
ANALISIS PERBANDINGAN METODE REGRESI LINIER DAN IMPORTANCE PERFORMANCE ANALYSIS (IPA) TERHADAP KEPUASAN PENGGUNA PADA LAYANAN E-GOVERNMENT MENGGUNAKAN METODE WEBQUAL MODIFIKASI
}

\author{
Frandika Septa*1, Anton Yudhana $^{2}$, Abdul Fadlil ${ }^{3}$ \\ 1,2,3 universitas Ahmad Dahlan Yogyakarta \\ Email: ${ }^{1}$ frandika.septa@gmail.com, ${ }^{2}$ eyudhana@mti.uad.ac.id, ${ }^{3}$ fadlil@mti.uad.ac.id \\ *Penulis Korespondensi
}

(Naskah masuk: 02 Agustus 2019, diterima untuk diterbitkan: 05 Oktober 2020)

\begin{abstract}
Abstrak
Layanan excellent merupakan layanan yang mampu memberikan rasa kepuasan bagi penggunanya, sehingga menimbulkan loyalitas terhadap layanan yang digunakan. Layanan E-Government menjadi penting untuk dilakukan penilaian kualitas layanannya terhadap kepuasan pengguna, karena salah satu tujuan dikembangkannya E-Government adalah memberikan pelayanan yang maksimal kepada masyarakat. Penelitian ini bertujuan untuk menganalisis tingkat kualitas layanan E-Government dalam kasus ini website SIMSARPRAS berdasarkan persepsi pengguna dari website SIMSARPRAS, yaitu madrasah dan operator kementerian agama. Jumlah responden adalah 500 orang yang dikumpulkan dari hasil penyebarah kuesioner secara online menggunakan Google Formulir. Metode dalam penelitian ini menggunakan metode WebQual modifikasi sebagai indikator dalam penyusunan kuesioner secara online, dan metode analisa menggunakan regresi linier berganda dan importance performance analysis (IPA). Hasil kuesioner diolah dan dilakukan pengujian instrumen dengan uji validitas dan uji reliabilitas untuk menunjukkan bahwa kuesioner layak dijadikan sebagai bahan penelitian lebih lanjut untuk dilakukan analisis data. Hasil analisis data diklasifikasikan berdasarkan persentase kepuasan pengguna terhadap layanan webiste SIMSARPRAS dengan tiga klasifikasi, yaitu baik, sedang dan buruk. Hasil analisis data menggunakan regresi linier berganda menunjukkan bahwa website SIMSARPRAS berkualitas sedang, sedangkan dengan IPA website berkualitas baik. Hasil analisis data menggunakan regresi linier berganda diketahui bahwa variabel bebas mampu mempengaruhi kepuasan pengguna sebesar $67,6 \%$ dan $32,4 \%$ dipengaruhi oleh variabel lainnya, sedangkan hasil dari IPA tingkat kesesuaian sebesar 96,22\% dan tingkat kesenjangan antara kinerja dan harapan dari layanan E-Government sebesar -0,12. Hasil dari penelitian ini memberikan kontribusi kepada kementerian agama khususnya sebagai pemilik website SIMSARPRAS untuk dijadikan sebagai bahan referensi dan evaluasi layanan SIMSARPRAS kedepannya.
\end{abstract}

Kata kunci: Analisis Perbandingan, E-Government, Importance Performance Analysis, Regresi Linier

\section{COMPARISON ANALYSIS OF LINE REGRESSION METHODS AND IMPORTANT PERFORMANCE ANAL YSIS (IPA) ON USER SATISFACTION IN E-GOVERNMENT SERVICES USING MODIFICATION WEBQUAL METHOD}

\begin{abstract}
Excellent service is a service that provides a sense of satisfaction for its users, thereby giving rise to loyalty to the services used. E-Government services are important to do. E-Government services to user satisfaction, because one of the goals that E-Government is developing to provide maximum service to the community. This study analyzes the level of quality of E-Government services in this case the SIMSARPRAS website based on user perceptions from the SIMSARPRAS website, namely madrasah and operators of the ministry of religion. The number of respondents was 500 people collected from the results of a questionnaire search using Google Forms. The method in this study uses the WebQual modification method as an indicator in testing online questionnaires, and the analysis method uses multiple linear regression and performance analysis of interest (IPA). The results of the questionnaire were processed and tested by an instrument with a validity test and a reliability test to prove the questionnaire was worthy of being used as further research material for data analysis. The results of data analysis are based on the percentage of user satisfaction with the SIMSARPRAS website service with three classifications, namely good, moderate and bad. The results of data analysis using multiple linear regression showed a medium-quality SIMSARPRAS site, whereas with a good quality website IPA. The results of data
\end{abstract}


analysis using multiple linear regression owned by independent variables can increase user satisfaction by $67.6 \%$ and $32.4 \%$ required by other variables, while the results of the IPA level of suitability are $96.22 \%$ and the level is in accordance with the results and expectations of the service E-Government is -0.12. The results of this study contribute to the special ministry of religion as the owner of the SIMSARPRAS website for use as a reference material and SIMSARPRAS service solutions going forward.

Keywords: Comparative Analysis, E-Government, Importance Performance Analysis, Linear Regression

\section{PENDAHULUAN}

Indonesia menjadi negara berkembang yang sudah menerapkan E-Government semenjak diterbitkannya Instruksi Presiden (INPRES) Nomor 3 Tahun 2003 tentang Kebijakan dan Strategi Nasional Pengembangan E-Government. Dalam INPRES tertulis tujuan dari pengembangan $E$ Government yaitu pemanfaatan teknologi informasi dalam meningkatkan pelayanan publik secara efektif dan efisien (Setneg, 2003). Selain dalam INPRES, pemanfaatan teknologi informasi dalam pemerintahan untuk memenuhi kebutuhan dan layanan yang efisien terhadap masyarakat tertuang dalam Peraturan Presiden (PERPRES) Nomor 95 Tahun 2018 tentang Sistem Pemerintahan Berbasis Elektronik, yang disingkat menjadi SPBE (Setneg, 2018). Penerapan E-Government pada pemerintahan dirasa tepat dilakukan, karena seiring berkembangnya jaman, teknologi informasi terus berkembang, terutama tahun 2011 Indonesia telah memasuki era industri 4.0 (Kemenperin, 2018).

E-Government merupakan suatu tindakan yang dilakukan oleh organisasi pemerintahan dalam menggunakan dan memanfaatkan teknologi informasi dan komunikasi untuk menjalankan tugas dalam pemerintahan untuk memberikan informasi dan melakukan pelayanan kepada publik atau masyarakat (Damanik and Purwaningsih, 2017). Dalam proses pengembangan E-Government, pada dasarkan memiliki 4 (empat) tahapan, yaitu persiapan, penerapan, pematangan dan pemantapan (Nugraha, 2018). E-Government menjadi salah satu contoh penerapan e-business pada bidang pemerintahan, sehingga diharapkan menjadi wadah dalam mempercepat penyampaian dan pertukaran informasi dari pemerintah ke masyarakat ataupun sebaliknya, dan menjadi solusi atas permasalahan pelayanan publik (Noveriyanto, Nisa and Bahtiar, 2018).

Dengan berkembangnya teknologi informasi, maka diperlukan juga pengujian terhadap teknologi tersebut, apakah sesuai dan tepat sasaran terhadap tujuan dikembangkannya teknologi tersebut. Penelitian ini menguji kualitas layanan $E$ Government pada kementerian agama, yaitu website Sistem Informasi Manajemen Sarana dan Prasarana (SIMSARPRAS). Pengujian dengan mengukur tingkat kepuasan pengguna website SIMSARPRAS, yaitu operator kementerian agama dan operator madrasah sebagai pengguna akhir. Gambar 1 adalah halaman depan pada website SIMSARPRAS tahun 2018.

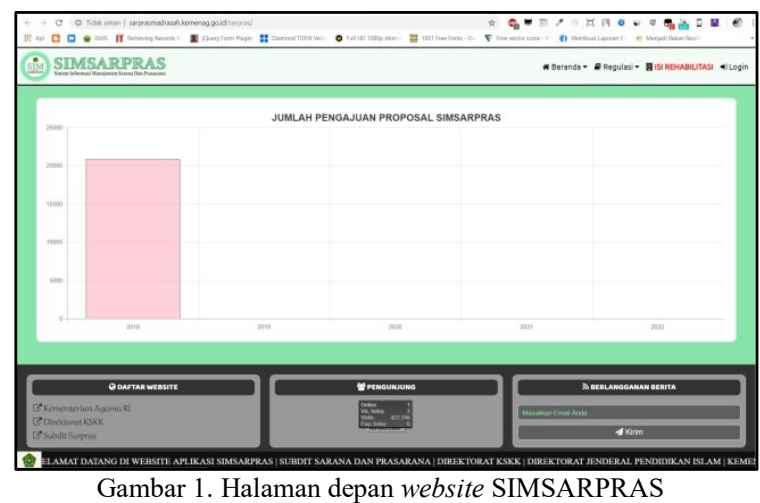

Website SIMSARPRAS dikembangkan sejak tahun 2017 dengan versi 1.0. SIMSARPRAS digunakan oleh madrasah seluruh Indonesia untuk melakukan pengajuan proposal permohonan dana bantuan sarana dan prasarana kepada kementerian agama, baik anggaran kabupaten/kota, provinsi dan pusat secara online yang beralamatkan di url http://sarprasmadrasah.kemenag.go.id/sarpras/. Sistem informasi ini merupakan penerapan dari layanan E-Government pada kementerian agama dalam menjalankan tugasnya melakukan pelayanan dan pemenuhan kebutuhan pendidikan madrasah yang dinaungi oleh Direktorat Jenderal Pendidikan Islam (Madrasah, 2018).

Kualitas layanan memiliki pengaruh yang penting dalam meningkatkan kepuasan pengguna (Oliver, 1980). Secara langsung kualitas layanan juga memiliki pengaruh dalam meningkatkan loyalitas dari pelanggan (Zeithaml, Berry and Parasuraman, 1996) dan secara tidak langsung loyalitas bisa meningkatkan kepuasan pengguna (Caruana, 2002). Kualitas layanan dapat dianalisis dengan melakukan analisis pada tingkat kesesuaian, tingkat kesenjangan (gap) dari persepsi pengguna layanan terhadap kinerja website dengan persepsi pengguna layanan terhadap harapan pada website yang digunakan dan melakukan analisis kuadran (Saputra, Suprapto and Rachmadi, 2018).

Penelitian ini menggunakan instrumen kuesioner sebagai data primer yang disebarkan kepada pengguna website SIMSARPRAS dengan menggunakan metode WebQual modifikasi dalam penyusunan instrumen kuesionernya. Metode WebQual dikembangkan oleh Barnes dan Vidgen pada tahun 2000. WebQual dalam penggunaannya 
bermanfaat dalam melakukan pengukuran kualitas situs dengan berdasarkan persepsi penggunanya (Barnes and Vidgen, 2003). WebQual yang dilakukan modifikasi dalam penelitian ini adalah WebQual 4.0 dengan empat dimensinya, dengan modifikasian penambahan satu dimensi yang dikembangkan oleh Hasan (2014) yaitu dimensi kualitas antarmuka pengguna (Hasan, 2014).

Hasil kuesioner yang telah dikumpulkan atau diunduh dari website Google Formulir kemudian dilakukan pengujian instrumen dengan uji validitas dan uji reliabilitas. Pengujian validitas adalah proses untuk menguji hasil kuesioner berstatus valid atau tidak dengan membandingkan nilai $r_{\text {hitung }}$ dengan nilai $r_{\text {tabel }}$. Nilai $r_{\text {hitung }}$ diperoleh dari hasil keluaran pearson corellation pada aplikasi SPSS dan nilai $\mathrm{r}_{\text {tabel }}$ diperoleh dari $\mathrm{r}_{\text {tabel }(\alpha=0,05 ; \mathrm{df}=\mathrm{n}-2) \text {. Ketentuan }}$ validnya suatu kuesioner adalah jika nilai $r_{\text {hitung }}$ lebih besar dari $r_{\text {tabel }}$ maka kuesioner dinyatakan valid, begitu juga sebaliknya (Arifin, 2017).

Pengujian reliabilitas adalah proses menguji hasil kuesioner berstatus reliabel atau tidak untuk menentukan kuesioner layak untuk diolah lebih lanjut sebagai bahan penelitian. Ketentuan dalam menentukan kuesioner reliabel atau tidak adalah dengan melihat nilai cronbach's alpha. Jika nilai cronbach's alpha lebih besar dari 0,70, maka kuesioner berstatus reliabel, begitu juga sebaliknya (Ghozali, 2016).

Metode WebQual modifikasi menjadi metode dalam penelitian ini, dan untuk menganalisis data yang siap diolah menggunakan metode regresi linier berganda dan importance performance analysis (IPA). Regresi linier berganda adalah salah satu metode analisis statistik yang digunakan untuk mengetahui atau atau tidaknya hubungan dua atau lebih variabel bebas dengan variabel terikat (Arifin, 2017). Variabel bebas pada penelitian ini terdiri dari dimensi kualitas kegunaan, dimensi kualitas informasi, dimensi kualitas interaksi layanan dan dimensi kualitas antarmuka pengguna. Sedangkan variabel terikat adalah dimensi kesan keseluruhan yang digunakan sebagai variabel kepuasan pengguna dalam analisis regresi linier berganda.

Importance performance analysis (IPA) adalah analisis yang diperkenalkan oleh Martila dan James (1977) menurut Magak dan Levenburg (dalam Budi Setiawan Santoso dan Muhammad Fauzi Anwar, 2015). IPA menggunakan tiga analisis dalam penggunaanya, yaitu analisis tingkat kesesuaian item pertanyaan, analisis tingkat kesesuaian (gap) dan analisis kuadran (Santoso, Anwar and Hermawati, 2015).

Peneliti terdahulu melakukan analisis kualitas layanan E-Government menggunakan metode WebQual 4.0 untuk instrumen kuesioner dan analisis data memakai analisis IPA. Hasil penelitian yang diperoleh adalah penilaian persepsi dan harapan website E-Government, rata-rata skor nilai persepsi lebih kecil dari pada rata-rata skor nilai harapan, yang mengartikan bahwa kualitas website masih kurang memuaskan pengguna (Sutejo, Soedijono and Sunyoto, 2018).

Peneliti selanjutnya melakukan analisis kualitas layanan E-Government menggunakan metode WebQual 4.0 untuk instru-men kuesioner dan memakai analisis regresi linier berganda. Hasil penelitian menunjukkan penilaian terhadap kualitas layanan E-Government dengan rata-rata skor 3,08 dari total skala penelitian yang berskala 4,00. Hasil tersebut mengartikan bahwa pengukuran kualitas layanan E-Government berkualitas baik berdasarkan persepsi penggunanya (Giyanti and Suparti, 2018).

Penelitian ini memiliki kebaharuan dalam ilmu penelitian dengan membandingkan metode analisis data antara regresi linier berganda dan IPA dengan metode penelitian WebQual 4.0 modifikasi. Pada penelitian terdahulu, kedua penelitian menggunakan metode WebQual 4.0 dan analisis data masingmasing menggunakan regresi linier berganda dan IPA.

Penelitian ini bertujuan untuk menganalisis tingkat kualitas layanan E-Government dalam kasus ini website SIMSARPRAS berdasarkan persepsi pengguna dari website SIMSARPRAS, yaitu madrasah dan operator kementerian agama. Sehingga hasil dari penelitian ini memberikan kontribusi kepada kementerian agama khususnya untuk menjadikan sebagai referensi atau bahan evaluasi pada website SIMSARPRAS selanjutnya, dan juga penelitian ini sebagai referensi bagi peneliti lain dalam melakukan penelitian yang terkait dengan E-Government kedepannya.

\section{METODE PENELITIAN}

Penentuan metode dalam penelitian ini adalah menggunakan metode WebQual 4.0 yang dimodifikasi dengan penambahan satu dimensi, yaitu dimensi kualitas antarmuka pengguna yang dikembangkan oleh Hasan (2014).

Analisis data kuesioner menggunakan dua metode, yaitu analisis regresi linier berganda dan importance performance analysis (IPA) yang telah dilakukan pengujian kelayakan kuesioner dengan uji validitas dan uji reliabilitas menggunakan aplikasi SPSS. Gambar 2 menunjukkan alur dalam penelitian ini.

Gambar 2 menunjukkan alur pada penelitian ini, analisa studi kasus merupakan proses pengumpulan data primer yang terdiri dari hasil kuesioner, data sekunder terkait pendukung dari data primer, seperti studi pustaka dari buku, jurnal, prosiding seminar, internet dan lainnya. Penentuan metode penelitian yang akan digunakan dan juga penentuan jumlah sampel pada penelitian dari jumlah populasi yang ada.

Analisis data merupakan proses setelah kuesioner penelitian diperoleh untuk selanjutnya dilakukan analisis data. Hasil kuesioner dilakukan pengujian validitas dan reliabilitas sebelum diproses 
untuk analisis regresi linier berganda dan IPA. Setelah diperoleh hasil penelitian, selanjutnya kesimpulan dan pemberian saran dari hasil penelitian.

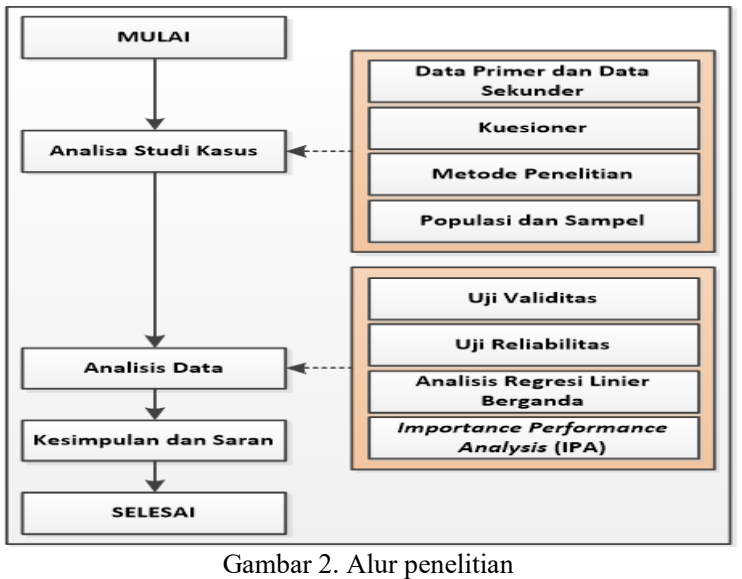

\subsection{Kuesioner}

Alat dalam penelitian ini menggunakan kuesioner yang disebarkan secara online menggunakan bantuan Google Formulir yang disediakan oleh Google. Kuesioner yang dibuat adalah berdasarkan metode WebQual modifikasian. Kuesioner yang disediakan bersifat tertutup, sehingga responden hanya memilih jawaban yang sudah disediakan oleh penulis, yang terdiri dari dua jenis jawaban dan empat skala jawaban bertipe likert. Setiap pertanyaan memiliki 2 pilihan respon, yaitu respon terhadap harapan dan kinerja. Gambar 3 menunjukkan skala pengukuran responden terhadap kuesioner.

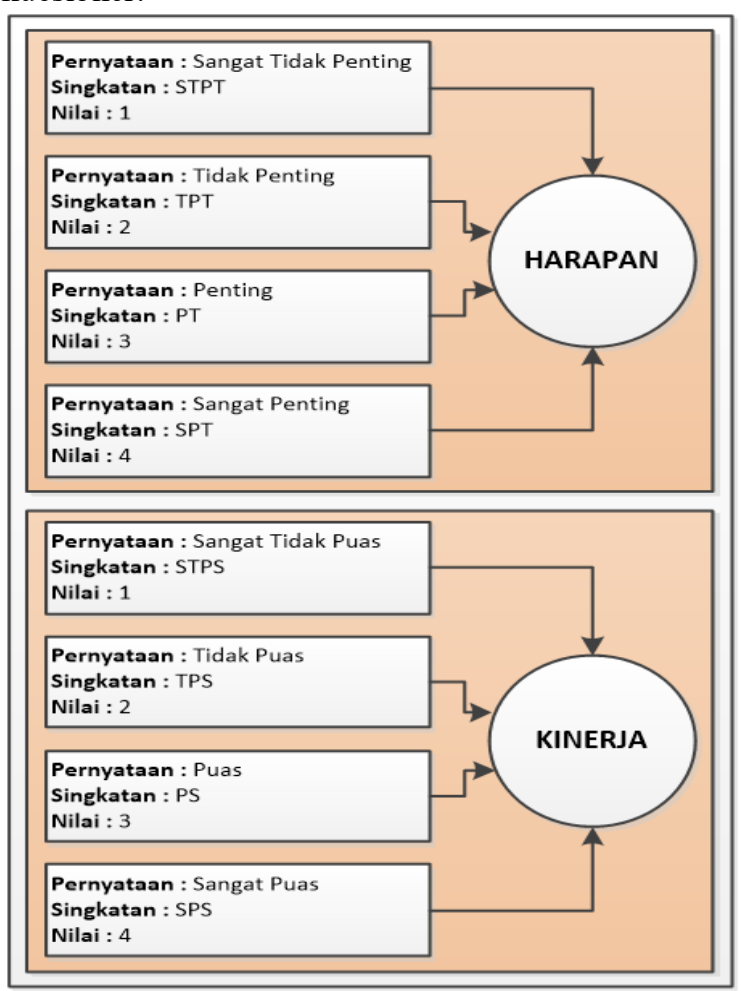

Gambar 3. Skala pengukuran responden
Berdasarkan gambar 3, terdapat 2 (dua) pemilihan jawaban terhadap pertanyaan kepada responden, yaitu jawaban untuk harapan dan untuk kinerja dari objek yang dinilai, yaitu layanan $E$ Government. Pada analisis menggunakan regresi linier berganda, hasil kuesioner yang digunakan dalam pengolahan data adalah jawaban dari responden pada persepsi tingkat kinerja dari website SIMSARPRAS. Sedangkan analisis menggunakan IPA, hasil kuesioner yang digunakan adalah jawaban dari responden pada persepsi tingkat harapan dan tingkat kinerja dari website SIMSARPRAS.

\subsection{WebQual Modifikasi}

Penulis menggunakan metode WebQual 4.0 karena dari hasil studi literatur, metode ini masih relevan digunakan dalam melakukan pengukuran layanan website.

Untuk kepentingan kebaharuan (novelty) dalam karya ilmiah atau penelitian, penulis melakukan modifikasi terhadap metode WebQual 4.0 dan membandingkan hasil analisis antara metode regresi linier berganda dan importance performance analysis (IPA) terhadap kepuasan pengguna dari objek penelitian, yaitu website SIMSARPRAS yang merupakan salah satu layanan E-Government yang dimiliki oleh pemerintah Indonesia.

Modifikasi yang dilakukan terhadap WebQual 4.0 adalah dengan penambahan 1 (satu) dimensi penelitian, yaitu kualitas antarmuka pengguna (Hasan, 2014). Sehingga terdapat 5 dimensi pada instrumen kuesioner penelitian ini, yaitu dimensi kualitas kegunaan, dimensi kualitas informasi, dimensi kualitas interaksi layanan, dimensi kualitas antarmuka pengguna dan dimensi kesan keseluruhan. Tabel 1 berikut ini adalah instrumen WebQual modifikasi pada penelitian ini.

Tabel 1. Instrumen Penelitian

\begin{tabular}{|c|c|c|}
\hline No & Instrumen & Kode \\
\hline \multicolumn{3}{|c|}{ WebQual 4.0 : Kualitas Kegunaan (Usability Quality) } \\
\hline 1 & $\begin{array}{l}\text { Pengguna dengan mudah untuk belajar } \\
\text { mengoperasikan }\end{array}$ & KKN 1 \\
\hline 2 & $\begin{array}{l}\text { Interaksi pengguna dengan website jelas dan } \\
\text { mudah dimengerti }\end{array}$ & KKN 2 \\
\hline 3 & Website mudah untuk dinavigasi & KKN 3 \\
\hline 4 & Website mudah untuk digunakan & KKN 4 \\
\hline 5 & Website memiliki tampilan yang menarik & KKN 5 \\
\hline 6 & Desain sesuai dengan jenis website & KKN 6 \\
\hline 7 & Website mengandung nilai kompetensi & KKN 7 \\
\hline 8 & $\begin{array}{l}\text { Website menciptakan pengalaman positif } \\
\text { bagi pengguna }\end{array}$ & KKN 8 \\
\hline \multicolumn{3}{|c|}{ WebQual 4.0 : Kualitas Informasi (Information Quality) } \\
\hline 9 & Website memberikan informasi yang akurat & KII 1 \\
\hline 10 & $\begin{array}{l}\text { Website memberikan informasi yang dapat } \\
\text { dipercaya }\end{array}$ & KII 2 \\
\hline 11 & $\begin{array}{l}\text { Website memberikan informasi yang tepat } \\
\text { waktu }\end{array}$ & KII 3 \\
\hline 12 & Website memberikan informasi yang relevan & KII 4 \\
\hline 13 & $\begin{array}{l}\text { Website memberikan informasi yang mudah } \\
\text { dimengerti }\end{array}$ & KII 5 \\
\hline 14 & Website memberikan informasi yang detail & KII 6 \\
\hline 15 & $\begin{array}{l}\text { Website menyajikan informasi dalam format } \\
\text { yang tepat }\end{array}$ & KII 7 \\
\hline
\end{tabular}




\begin{tabular}{|c|c|c|}
\hline \multicolumn{3}{|c|}{$\begin{array}{c}\text { WebQual 4.0 : Kualitas Interaksi Layanan (Service } \\
\text { Interaction Quality) }\end{array}$} \\
\hline 16 & Website memiliki reputasi yang baik & KIL 1 \\
\hline 17 & $\begin{array}{l}\text { Pengguna merasa aman ketika melakukan } \\
\text { transaksi }\end{array}$ & KIL 2 \\
\hline 18 & $\begin{array}{l}\text { Pengguna merasa aman terhadap informasi } \\
\text { pribadi }\end{array}$ & KIL 3 \\
\hline 19 & $\begin{array}{l}\text { Website memberikan ruang untuk } \\
\text { personalisasi }\end{array}$ & KIL 4 \\
\hline 20 & Website memberi ruang untuk komunitas & KIL 5 \\
\hline 21 & $\begin{array}{l}\text { Website memberikan kemudahan untuk } \\
\text { berkomunikasi dengan organisasi }\end{array}$ & KIL 6 \\
\hline 22 & $\begin{array}{l}\text { Pengguna merasa yakin bahwa layanan yang } \\
\text { diterima sesuai dengan yang dijanjikan }\end{array}$ & KIL 7 \\
\hline \multicolumn{3}{|c|}{$\begin{array}{c}\text { Hasan (2014) : Kualitas Antarmuka Pengguna (User } \\
\text { Interface Quality) }\end{array}$} \\
\hline 23 & Website menggunakan gambar yang tepat & KAP 1 \\
\hline 24 & $\begin{array}{l}\text { Website menggunakan font (huruf) yang } \\
\text { sesuai }\end{array}$ & KAP 2 \\
\hline 25 & Website menggunakan warna yang sesuai & KAP 3 \\
\hline 26 & $\begin{array}{l}\text { Website menggunakan desain halaman yang } \\
\text { sesuai }\end{array}$ & KAP 4 \\
\hline 27 & Link pada website bekerja dengan baik & KAP 5 \\
\hline 28 & Kecepatan download pada halaman website & KAP 6 \\
\hline \multicolumn{3}{|c|}{ WebQual 4.0 : Kesan Keseluruhan (Overall Impression) } \\
\hline 29 & Penilaian website secara keseluruhan & OVL 1 \\
\hline
\end{tabular}

\subsection{Sampel Penelitian}

Penulis perlu menentukan jumlah sampel yang akan digunakan dalam penelitian ini, karena jumlah pengguna dari website SIMSARPRAS sekitar 77.884 orang/lembaga, sehingga perlu menggunakan sampel untuk mewakili dari seluruh pengguna website SIMSARPRAS. Dalam menentukan jumlah sampel, penulis menggunakan persamaan rumus yang diperkenalkan oleh Slovin (dalam Johar Arifin, 2017) sebagai berikut:

$n=\frac{N}{\left(1+N \cdot M o e^{2}\right)}$

Dimana:

n $\quad$ = Jumlah sampel penelitian

$\mathrm{N}=$ Jumlah populasi

Moe2 = Batas kesalahan maksimum

Pengguna pada website SIMSARPRAS adalah operator kementerian agama dan operator madrasah yang berjumlah 77.884 orang/lembaga, sehingga diketahui jumlah $\mathrm{N}$ adalah 77.884, dengan batas kesalahan maksimum 0,05. Sehingga perhitungan jumlah sampel sebagai berikut:

$$
\begin{aligned}
& n=\frac{77.884}{\left(1+77.884 \times 0,05^{2}\right)} \\
& n=397,96
\end{aligned}
$$

Berdarakan hasil perhitungan jumlah sampel, jumlah sampel yang didapat adalah 397,96 orang atau \pm 398 orang. Dari hasil tersebut, penulis menambahkan jumlah sampel untuk penelitian ini menjadi 500 orang agar lebih ideal.

\subsection{Klasifikasi Kualitas Website SIMSARPRAS}

Klasifikasi kualitas website perlu dilakukan untuk mengetahui hasil dari analisis regresi linier berganda dan IPA terhadap website SIMSARPRAS berkualitas baik, sedang atau buruk. Gambar 4 menunjukkan diagram klasifikasi kualitas website SIMSARPRAS.

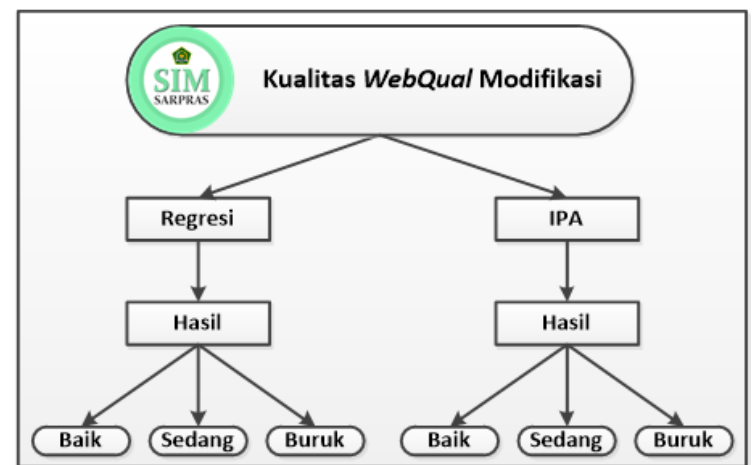

Gambar 4. Diagram klasifikasi website SIMSARPRAS

Klasifikasi berdasarkan Gambar 4 ada tiga, yaitu baik, sedang dan buruk. Untuk menentukan klasifikasi tersebut, penulis menentukan range nilai sebagai berikut:

- Jika nilai hasil analisis $0 \% \geq 55 \%$, maka kualitas website SIMSARPRAS adalah berkualitas buruk.

- Jika nilai hasil analisis 56\%-75\%, maka kualitas website SIMSARPRAS adalah berkualitas sedang.

- Jika nilai hasil analisis 76\%-100\%, maka kualitas website SIMSARPRAS adalah bekualitas baik.

\section{HASIL DAN PEMBAHASAN}

Berdasarkan Gambar 2, hasil dan pembahasan penelitian ini adalah pada proses analisis data, yang menampilkan hasil pengujian kelayakan instrumen untuk digunakan dalam penelitian menggunakan uji validitas dan uji reliabilitas, hasil analisis data menggunakan regresi linier berganda dan IPA.

\subsection{Uji Validitas}

Hasil kuesioner yang telah dikumpulkan, selanjutnya dilakukan pengujian validitas. Uji validitas perlu dilakukan untuk mengetahui hasil kuesioner valid atau tidak, pengujian dilakukan dengan menggunakan aplikasi SPSS terhadap jawaban harapan dan kinerja.

Dari hasil uji validitas menggunakan SPSS dengan membandingkan nilai dari $\mathrm{r}_{\text {hitung }}$ (pearson corellation) dengan $r_{\text {tabel, diperoleh hasil bahwa }}$ semua item pertanyaan pada kuesioner berstatus valid. Tabel 2 adalah hasil uji validitas dari jawaban responden pada kuesioner penelitian ini. 


\begin{tabular}{|c|c|c|c|c|c|c|c|}
\hline \multirow[b]{2}{*}{$\begin{array}{l}\mathbf{N} \\
\mathbf{0}\end{array}$} & \multirow[b]{2}{*}{ Item } & \multicolumn{3}{|c|}{ HARAPAN } & \multicolumn{3}{|c|}{ KINERJA } \\
\hline & & $\mathbf{r}_{\text {hitung }}$ & $\mathbf{r}_{\text {tabel }}$ & $\begin{array}{c}\text { Statu } \\
\text { s }\end{array}$ & $\mathbf{r}_{\text {hitung }}$ & $\mathbf{r}_{\text {tabel }}$ & $\begin{array}{c}\text { Statu } \\
\text { s }\end{array}$ \\
\hline 1 & KKN 1 & 0,665 & 0,074 & Valid & 0,669 & 0,074 & Valid \\
\hline 2 & KKN 2 & 0,720 & 0,074 & Valid & 0,782 & 0,074 & Valid \\
\hline 3 & KKN 3 & 0,710 & 0,074 & Valid & 0,752 & 0,074 & Valid \\
\hline 4 & KKN 4 & 0,790 & 0,074 & Valid & 0,791 & 0,074 & Valid \\
\hline 5 & KKN 5 & 0,698 & 0,074 & Valid & 0,760 & 0,074 & Valid \\
\hline 6 & KKN 6 & 0,711 & 0,074 & Valid & 0,761 & 0,074 & Valid \\
\hline 7 & KKN 7 & 0,748 & 0,074 & Valid & 0,778 & 0,074 & Valid \\
\hline 8 & KKN 8 & 0,761 & 0,074 & Valid & 0,772 & 0,074 & Valid \\
\hline 9 & KII 1 & 0,785 & 0,074 & Valid & 0,815 & 0,074 & Valid \\
\hline 10 & KII 2 & 0,845 & 0,074 & Valid & 0,822 & 0,074 & Valid \\
\hline 11 & KII 3 & 0,801 & 0,074 & Valid & 0,816 & 0,074 & Valid \\
\hline 12 & KII 4 & 0,823 & 0,074 & Valid & 0,826 & 0,074 & Valid \\
\hline 13 & KII 5 & 0,823 & 0,074 & Valid & 0,820 & 0,074 & Valid \\
\hline 14 & KII 6 & 0,822 & 0,074 & Valid & 0,823 & 0,074 & Valid \\
\hline 15 & KII 7 & 0,854 & 0,074 & Valid & 0,848 & 0,074 & Valid \\
\hline 16 & KIL 1 & 0,827 & 0,074 & Valid & 0,827 & 0,074 & Valid \\
\hline 17 & KIL 2 & 0,810 & 0,074 & Valid & 0,797 & 0,074 & Valid \\
\hline 18 & KIL 3 & 0,803 & 0,074 & Valid & 0,807 & 0,074 & Valid \\
\hline 19 & KIL 4 & 0,802 & 0,074 & Valid & 0,796 & 0,074 & Valid \\
\hline 20 & KIL 5 & 0,759 & 0,074 & Valid & 0,792 & 0,074 & Valid \\
\hline 21 & KIL 6 & 0,776 & 0,074 & Valid & 0,795 & 0,074 & Valid \\
\hline 22 & KIL 7 & 0,794 & 0,074 & Valid & 0,818 & 0,074 & Valid \\
\hline 23 & KAP 1 & 0,782 & 0,074 & Valid & 0,831 & 0,074 & Valid \\
\hline 24 & KAP 2 & 0,738 & 0,074 & Valid & 0,777 & 0,074 & Valid \\
\hline 25 & KAP 3 & 0,732 & 0,074 & Valid & 0,759 & 0,074 & Valid \\
\hline 26 & KAP 4 & 0,758 & 0,074 & Valid & 0,779 & 0,074 & Valid \\
\hline 27 & KAP 5 & 0,800 & 0,074 & Valid & 0,786 & 0,074 & Valid \\
\hline 28 & KAP 6 & 0,769 & 0,074 & Valid & 0,788 & 0,074 & Valid \\
\hline 29 & OVL 1 & 0,788 & 0,074 & Valid & 0,831 & 0,074 & Valid \\
\hline
\end{tabular}

\subsection{Uji Reliabilitas}

Pengujian instrumen penelitian selanjutnya adalah uji reliabilitas. Pengujian terhadap hasil kuesioner pada tingkat harapan dan tingkat kinerja website SIMSARPRAS berdasarkan persepsi penggunanya. Hasil uji reliabilitas menunjukkan bahwa tingkat harapan dan tingkat kinerja reliabel untuk digunakan lebih lanjut. Tabel 3 adalah hasil uji reliabilitas dari jawaban responden pada kuesioner penelitian ini.

Tabel 3. Hasil Uji Reliabilitas Tingkat Harapan dan Kinerja

\begin{tabular}{cccc}
\hline No & Tingkat & Cranbach's Alpha & Status \\
\hline 1 & Harapan & 0,976 & Reliabel \\
2 & Kinerja & 0,979 & Reliabel \\
\hline
\end{tabular}

Berdasarkan Tabel 3, hasil uji reliabilitas pada tingkat harapan dan tingkat kinerja adalah reliabel, karena semua nilai cronbach's alpha lebih besar dari 0,70 (Ghozali, 2016).

Dari hasil uji instrumen pada uji validitas dan uji reliabilitas, maka kuesioner pada penelitian ini layak untuk dijadikan bahan penelitian.

\subsection{Regresi Linier Berganda}

Variabel bebas dalam penelitian ini terdiri dari dimensi kualitas kegunaan $\left(\mathrm{X}_{1}\right)$, kualitas informasi $\left(\mathrm{X}_{2}\right)$, kualitas interaksi layanan $\left(\mathrm{X}_{3}\right)$ dan kualitas antarmuka pengguna $\left(\mathrm{X}_{4}\right)$. Sedangkan variabel terikat adalah dimensi kesan keseluruhan (Y) yang digunakan sebagai kepuasan pengguna (user satisfaction). Untuk mengetahui tingkat pengaruh dari variabel bebas terhadap variabel terikat pada penelitian ini menggunakan persamaan (2) regresi linier berganda berikut ini.
$Y=a+b_{1} X_{1}+b_{2} X_{2}+b_{3} X_{3}+b_{4} X_{4}$

Dimana:

$\mathrm{Y} \quad=$ Kepuasan pengguna layanan

a $\quad=$ Konstanta

$\mathrm{b} \quad=$ Angka koefisien regresi

$\mathrm{X}_{1} \quad=$ Dimensi kualitas kegunaan

$\mathrm{X}_{2} \quad=$ Dimensi kualitas informasi

$\mathrm{X}_{3} \quad=$ Dimensi kualitas interaksi layanan

$\mathrm{X}_{4}=$ Dimensi kualitas antarmuka pengguna

Tabel 4. Keluaran Regresi Linier Berganda

\begin{tabular}{cccccc}
\hline & $\begin{array}{c}\text { Unstandardized } \\
\text { Coefficiebts }\end{array}$ & $\begin{array}{c}\text { Standardi } \\
\text { zed } \\
\text { Coefficie } \\
\text { nts }\end{array}$ & & \\
\cline { 2 - 4 } Model & B & $\begin{array}{c}\text { Std. } \\
\text { Error }\end{array}$ & Beta & T & Sig. \\
\hline (Constant) & $-0,139$ & 0,110 & & $-1,267$ & 0,206 \\
X1 & 0,111 & 0,068 & 0,088 & 1,650 & 0,100 \\
X2 & 0,262 & 0,071 & 0,229 & 3,705 & 0,000 \\
X3 & 0,243 & 0,075 & 0,209 & 3,262 & 0,001 \\
X4 & 0,425 & 0,065 & 0,348 & 6,564 & 0,000 \\
\hline
\end{tabular}

Tabel 4 menunjukkan hasil keluaran dari analisis data regresi linier berganda pada tingkat kinerja menggunakan aplikasi SPSS. Berdasarkan hasil tersebut, hasil keluaran dimasukkan kedalam persamaan (2) berikut ini: $Y=-0,139+0,111 X_{1}+0,262 X_{2}+0,243 X_{3}+$
$0,425 X_{4}$

Berdasarkan persamaan diatas, diketahui nilai konstanta sebesar $-0,139$, yang mengartikan nilai kepuasan pengguna terhadap layanan E-Government pada saat layanan bernilai nol. Selanjutnya diketahui nilai layanan E-Government sebagai berikut ini:

- $\quad$ Setiap ada kenaikan nilai satu kesatuan pada dimensi $\mathrm{X}_{1}$ atau dimensi kualitas kegunaan, akan menaikkan tingkat kepuasan pengguna sebesar 0,111 terhadap layanan E-Government.

- $\quad$ Setiap ada kenaikan nilai satu kesatuan pada dimensi $\mathrm{X}_{2}$ atau dimensi kualitas informasi, akan menaikkan tingkat kepuasan pengguna sebesar 0,262 terhadap layanan E-Government.

- $\quad$ Setiap ada kenaikan nilai satu kesatuan pada dimensi $\mathrm{X}_{3}$ atau dimensi kualitas interaksi layanan, akan menaikkan tingkat kepuasan pengguna sebesar 0,243 terhadap layanan $E$ Government.

- $\quad$ Setiap ada kenaikan nilai satu kesatuan pada dimensi $\mathrm{X}_{4}$ atau dimensi kualitas antarmuka pengguna, akan menaikkan tingkat kepuasan pengguna sebesar 0,425 terhadap layanan $E$ Government.

Selanjutnya untuk mengetahui besaran nilai yang dihasilkan variabel bebas untuk mempengaruhi nilai variabel terikat menggunakan keluaran dari koefisien determinasi pada Tabel 5 berikut ini: 
Tabel 5. Keluaran Koefisien Determinasi

\begin{tabular}{ccccc}
\hline Model & $\mathbf{R}$ & $\begin{array}{c}\mathbf{R} \\
\text { Square }\end{array}$ & $\begin{array}{c}\text { Adjusted } \mathbf{R} \\
\text { Square }\end{array}$ & $\begin{array}{c}\text { Std. Error of } \\
\text { the Estimate }\end{array}$ \\
\hline 1 & $0,822^{\mathrm{a}}$ & 0,676 & 0,674 & 0,33679 \\
\hline
\end{tabular}

Berdasarkan Tabel 5, diketahui nilai $\mathrm{R}$ (korelasi) sebesar 0,822 dan R Square (koefisien determinasi) sebesar 0,676 (67,6\%). Dari hasil tersebut, bisa disimpulkan bahwa:

- Hasil koefisien determinasi, mengartikan bahwa variabel terikat (Y) atau kepuasan pengguna mampu dipengaruhi oleh variabel bebas $\left(\mathrm{X}_{1}, \mathrm{X}_{2}, \mathrm{X}_{3}\right.$ dan $\left.\mathrm{X}_{4}\right)$ sebesar $67,6 \%$.

- Selain dari variabel bebas pada penelitian ini, kepuasan pengguna dipengaruhi oleh variabel lain diluar penelitian ini sebesar $32,4 \%$.

- Hasil korelasi yang bernilai 0,822 mengartikan bahwa hubungan antara variabel bebas dengan variabel terikat pada penelitian ini sangat kuat, karena berada pada rentan nilai $0,80-1,000$

\subsection{Importance Performance Analysis (IPA)}

Terdapat tiga analisis yang harus dilakukan dalam analisis menggunakan IPA, yaitu analisis tingkat kesesuaian, analisis tingkat kesenjangan (gap) dan analisis kuadran IPA atau diagram kartesius.

\subsubsection{Analisis Tingkat Kesesuaian}

Analisis yang pertama dilakukan dalam IPA adalah analisis kesesuaian. Analisis tingkat kesesuaian terdapat dua analisis, yaitu analisis tingkat kesesuaian per-item pertanyaan dan analisis tingkat kesesuaian total. Dalam penghitungan analisis tingkat kesesuaian per-item ditunjukkan pada persamaan rumus (3) dan perhitungan analisis tingkat kesesuaian total ditunjukkan pada persamaan rumus (4).

$T k i=\frac{X_{i}}{Y_{i}} x 100 \%$

Dimana:

Tki= Tingkat kesesuaian per-item

$\mathrm{X}_{\mathrm{i}} \quad=$ Skor kinerja

$\mathrm{Y}_{\mathrm{i}} \quad=$ Skor harapan

$\sum T k i=\frac{\sum X_{i}}{\sum Y_{i}} x 100 \%$

Dimana:

$\sum$ Tki $=$ Tingkat kesesuaian total

$\sum \mathrm{X}_{\mathrm{i}} \quad=$ Jumlah skor kinerja

$\sum \mathrm{Y}_{\mathrm{i}} \quad=$ Jumlah skor harapan
- $\quad$ Tingkat kesesuaian dimensi kualitas kegunaan Tabel 6. Tingkat Kesesuaian Dimensi Kualitas Kegunaan

\begin{tabular}{ccccc}
\hline No & Item & Skor Kinerja & Skor Harapan & Tki \\
\hline 1 & KKN 1 & 1.623 & 1.727 & $93,98 \%$ \\
2 & KKN 2 & 1.621 & 1.686 & $96,14 \%$ \\
3 & KKN 3 & 1.619 & 1.663 & $97,35 \%$ \\
4 & KKN 4 & 1.631 & 1.705 & $95,66 \%$ \\
5 & KKN 5 & 1.631 & 1.670 & $97,66 \%$ \\
6 & KKN 6 & 1.620 & 1.652 & $98,06 \%$ \\
7 & KKN 7 & 1.612 & 1.667 & $96,70 \%$ \\
8 & KKN 8 & 1.636 & 1.687 & $96,98 \%$ \\
\hline \multicolumn{2}{c}{ Total } & $\mathbf{1 2 . 9 9 3}$ & $\mathbf{1 3 . 4 5 7}$ & $\mathbf{9 6 , 5 5 \%}$ \\
\hline
\end{tabular}

- $\quad$ Tingkat kesesuaian dimensi kualitas informasi Tabel 7. Tingkat Kesesuaian Dimensi Kualitas Informasi

\begin{tabular}{ccccc}
\hline No & Item & Skor Kinerja & Skor Harapan & Tki \\
\hline 9 & KII 1 & 1.621 & 1.706 & $95,02 \%$ \\
10 & KII 2 & 1.644 & 1.719 & $95,64 \%$ \\
11 & KII 3 & 1.594 & 1.683 & $94,71 \%$ \\
12 & KII 4 & 1.618 & 1.688 & $95,85 \%$ \\
13 & KII 5 & 1.629 & 1.703 & $95,65 \%$ \\
14 & KII 6 & 1.624 & 1.696 & $95,75 \%$ \\
15 & KII 7 & 1.622 & 1.686 & $96,20 \%$ \\
\hline \multicolumn{2}{c}{ Total } & $\mathbf{1 1 . 3 5 2}$ & $\mathbf{1 1 . 8 8 1}$ & $\mathbf{9 5 , 5 5 \%}$ \\
\hline
\end{tabular}

- Tingkat kesesuaian dimensi kualitas interaksi layanan

Tabel 8. Tingkat Kesesuaian Dimensi Kualitas Interaksi Layanan

\begin{tabular}{ccccc}
\hline No & Item & Skor Kinerja & Skor Harapan & Tki \\
\hline 16 & KIL 1 & 1.597 & 1.658 & $96,32 \%$ \\
17 & KIL 2 & 1.630 & 1.682 & $96,91 \%$ \\
18 & KIL 3 & 1.635 & 1.691 & $96,69 \%$ \\
19 & KIL 4 & 1.603 & 1.652 & $97,03 \%$ \\
20 & KIL 5 & 1.566 & 1.642 & $95,37 \%$ \\
21 & KIL 6 & 1.571 & 1.645 & $95,50 \%$ \\
22 & KIL 7 & 1.563 & 1.653 & $94,56 \%$ \\
\hline \multicolumn{6}{c}{ Total } & $\mathbf{1 1 . 1 6 5}$ & $\mathbf{1 1 . 6 2 3}$ & $\mathbf{9 6 , 0 6 \%}$ \\
\hline
\end{tabular}

- $\quad$ Tingkat kesesuaian dimensi kualitas antarmuka pengguna

Tabel 9. Tingkat Kesesuaian Dimensi Kualitas Antarmuka Pengguna

\begin{tabular}{ccccc}
\hline No & Item & Skor Kinerja & Skor Harapan & Tki \\
\hline 23 & KAP 1 & 1.619 & 1.672 & $96,83 \%$ \\
24 & KAP 2 & 1.623 & 1.668 & $97,30 \%$ \\
25 & KAP 3 & 1.614 & 1.639 & $98,47 \%$ \\
26 & KAP 4 & 1.629 & 1.670 & $97,54 \%$ \\
27 & KAP 5 & 1.612 & 1.694 & $95,16 \%$ \\
28 & KAP 6 & 1.613 & 1.691 & $95,39 \%$ \\
\hline \multicolumn{2}{c}{ Total } & $\mathbf{9 . 7 1 0}$ & $\mathbf{1 0 . 0 3 4}$ & $\mathbf{9 6 , 7 7 \%}$ \\
\hline
\end{tabular}

- $\quad$ Tingkat kesesuaian total Tabel 10. Tingkat Kesesuaian Total

\begin{tabular}{ccc}
\hline Skor Kinerja & Skor Harapan & $\sum \mathbf{T k i}$ \\
\hline 45.220 & 46.995 & $96,22 \%$ \\
\hline
\end{tabular}

Berdasarkan Tabel 6,7,8 dan 9 diketahui bahwa nilai tingkat kesesuaian pada dimensi kualitas kegunaan sebesar 96,55\%, dimensi kualitas informasi sebesar $95,55 \%$, dimensi kualitas interaksi layanan sebesar $96,06 \%$ dan dimensi kualitas antarmuka pengguna sebesar $96,77 \%$. Sedangkan Tabel 10 adalah nilai tingkat kesesuaian total sebesar $96,22 \%$. Dari hasil tingkat kesesuaian perdimensi dan tingkat kesesuaian total, dapat disimpulkan bahwa pengguna kurang puas terhadap layanan website SIMSARPRAS. 


\subsubsection{Analisis Tingkat Kesenjangan (gap)}

Setelah analisis tingkat kesesuaian selesai, selanjutnya analisis tingkat kesenjangan (gap). Untuk menghitung nilai gap, yaitu dengan perhitungan rata-rata kinerja dikurangi rata-rata harapan. Berikut ini hasil perhitungan nilai gap pada penelitian ini.

- $\quad$ Tingkat gap dimensi kualitas kegunaan

\begin{tabular}{|c|c|c|c|c|}
\hline No & Item & $\begin{array}{c}\text { Rata-rata } \\
\text { Kinerja }\end{array}$ & $\begin{array}{l}\text { Rata-rata } \\
\text { Harapan }\end{array}$ & Gap \\
\hline 1 & KKN 1 & 3,25 & 3,45 & $-0,20$ \\
\hline 2 & KKN 2 & 3,24 & 3,37 & $-0,13$ \\
\hline 3 & KKN 3 & 3,24 & 3,33 & $-0,09$ \\
\hline 4 & KKN 4 & 3,26 & 3,41 & $-0,15$ \\
\hline 5 & KKN 5 & 3,26 & 3,34 & $-0,08$ \\
\hline 6 & KKN 6 & 3,24 & 3,30 & $-0,06$ \\
\hline 7 & KKN 7 & 3,22 & 3,33 & $-0,11$ \\
\hline 8 & KKN 8 & 3,27 & 3,37 & $-0,10$ \\
\hline \multicolumn{2}{|c|}{ Rata-rata } & 3,25 & 3,36 & $-0,12$ \\
\hline
\end{tabular}

- $\quad$ Tingkat gap dimensi kualitas informasi

\begin{tabular}{ccccc}
\multicolumn{5}{c}{ Tabel 12. Tingat Gap Dimensi Kualitas Informasi } \\
\hline No & Item & $\begin{array}{c}\text { Rata-rata } \\
\text { Kinerja }\end{array}$ & $\begin{array}{c}\text { Rata-rata } \\
\text { Harapan }\end{array}$ & Gap \\
\hline 1 & KII 1 & 3,24 & 3,41 & $-0,17$ \\
2 & KII 2 & 3,29 & 3,44 & $-0,15$ \\
3 & KII 3 & 3,19 & 3,37 & $-0,18$ \\
4 & KII 4 & 3,24 & 3,38 & $-0,14$ \\
5 & KII 5 & 3,26 & 3,41 & $-0,15$ \\
6 & KII 6 & 3,25 & 3,39 & $-0,14$ \\
7 & KII 7 & 3,24 & 3,37 & $-0,13$ \\
\hline \multicolumn{5}{c}{ Rata-rata } \\
\hline
\end{tabular}

- Tingkat gap dimensi kualitas interaksi layanan

\begin{tabular}{|c|c|c|c|c|}
\hline No & Item & $\begin{array}{c}\text { Rata-rata } \\
\text { Kinerja }\end{array}$ & $\begin{array}{l}\text { Rata-rata } \\
\text { Harapan }\end{array}$ & Gap \\
\hline 1 & KIL 1 & 3,19 & 3,32 & $-0,13$ \\
\hline 2 & KIL 2 & 3,26 & 3,36 & $-0,10$ \\
\hline 3 & KIL 3 & 3,27 & 3,38 & $-0,11$ \\
\hline 4 & KIL 4 & 3,21 & 3,30 & $-0,09$ \\
\hline 5 & KIL 5 & 3,13 & 3,28 & $-0,15$ \\
\hline 6 & KIL 6 & 3,14 & 3,29 & $-0,15$ \\
\hline 7 & KIL 7 & 3,13 & 3,31 & $-0,18$ \\
\hline \multicolumn{2}{|c|}{ Rata-rata } & 3,19 & 3,32 & $-0,13$ \\
\hline
\end{tabular}

- $\quad$ Tingkat gap dimensi kualitas antaramuka pengguna

\begin{tabular}{|c|c|c|c|c|}
\hline No & Item & $\begin{array}{l}\text { Rata-rata } \\
\text { Kinerja }\end{array}$ & $\begin{array}{l}\text { Rata-rata } \\
\text { Harapan }\end{array}$ & Gap \\
\hline 1 & KAP 1 & 3,24 & 3,34 & $-0,10$ \\
\hline 2 & KAP 2 & 3,25 & 3,34 & $-0,09$ \\
\hline 3 & KAP 3 & 3,23 & 3,28 & $-0,05$ \\
\hline 4 & KAP 4 & 3,26 & 3,34 & $-0,08$ \\
\hline 5 & KAP 5 & 3,22 & 3,39 & $-0,17$ \\
\hline 6 & KAP 6 & 3,23 & 3,38 & $-0,15$ \\
\hline \multicolumn{2}{|c|}{ Rata-rata } & 3,24 & 3,35 & $-0,11$ \\
\hline
\end{tabular}

- $\quad$ Tingkat rata-rata gap Tabel 15. Tingakat Rata-rata Gap

\begin{tabular}{ccc}
\hline Rata-rata Kinerja & Rata-rata Harapan & Rata-rata Gap \\
\hline 3,26 & 3,38 & $-0,12$ \\
\hline
\end{tabular}

Berdasarkan Tabel 11,12,13,14 dan 15, diketahui semua gap bernilai negatif (-), dengan nilai rata-rata gap bernilai -0,12. Dari hasil perhitungan tersebut, maka diketahui bahwa semua dimensi saat ini belum bisa memenuhi kepuasan pengguna, karena harapan pengguna lebih tinggi daripada kinerja website SIMSARPRAS.

\subsubsection{Diagram kartesius}

Diagram kartesius diperlukan untuk pembagian wilayah kuadran terhadap item-item yang dilakukan penghitungan, yaitu tingkat harapan dan tingkat kinerja dari layanan website SIMSARPRAS.

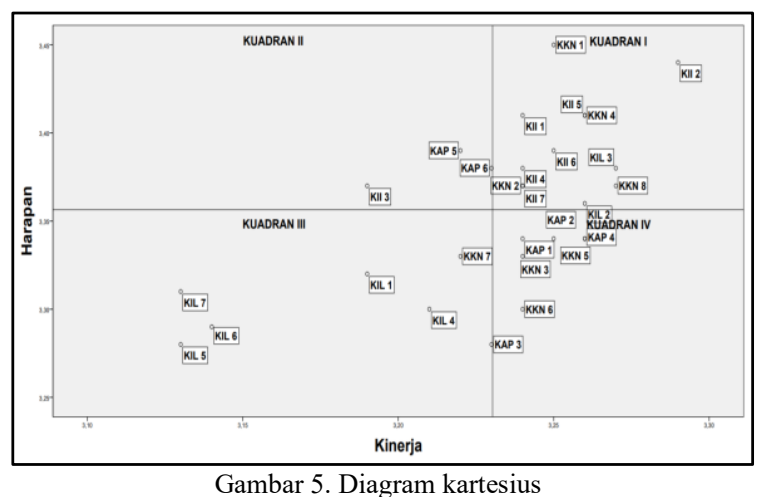

Berdasarkan Gambar 5, dapat diambil kesimpulan sebagai berikut ini:

- $\quad$ Item KKN 1, KKN 2, KKN 4, KKN 8, KII 1, KII 2, KII 4, KII 5, KII 6, KII 7, KIL 2 dan KIL 3 berada pada kuadran I yang artinya berada pada daerah yang harus dipertahankan, karena harapan tinggi dan kinerja juga tinggi.

- $\quad$ Item KII 3, KAP 5 dan KAP 6 berada pada kuadran II yang artinya berada pada daerah prioritas pertama, karena harapan tinggi tetapi kinerja rendah.

- $\quad$ Item KKN 7, KIL 1, KIL 4, KIL 5, KIL 6, KIL 7 dan KAP 3 berada pada kuadran III yang artinya berada pada daerah prioritas rendah, karena harapan rendah dan kinerja juga rendah.

- $\quad$ Item KKN 3, KKN 5, KKN 6, KAP 1, KAP 4 dan KAP 2 berada pada kuadran IV yang artinya berada pada daerah berlebihan, karena harapan rendah namun kinerja tinggi.

Berdasarkan hasil penelitian menggunakan regresi linier berganda, diketahui koefisien dimensi kualitas kegunaan sebesar 0,111, dimensi kualitas informasi sebesar 0,262, dimensi kualitas interaksi layanan sebesar 0,243 dan dimensi kualitas 
antarmuka pengguna sebesar 0,425. Dari hasil tersebut, dapat disimpulkan bahwa dimensi yang paling besar pengaruhnya terhadap kepuasan pengguna adalah dimensi kualitas antarmuka pengguna, dan dimensi yang paling rendah pengaruhnya terhadap kepuasan pengguna adalah dimensi kualitas kegunaan. Koefisien determinasi menunjukkan angka 0,676 atau $67,6 \%$, yang mengartikan bahwa kepuasan pengguna dapat dipengaruhi oleh variabel bebas sebesar $67,6 \%$, sedangkan sisanya sebesar $32,4 \%$ dipengaruhi oleh variabel lainnya diluar variabel WebQual modifikasi penelitian ini. Kemudian diketahui nilai korelasi antara variabel bebas dengan variabel terikat sebesar 0,822 , yang mengartikan hubungan antara variabel bebas terhadap variabel terikat sangat kuat.

Berdasarkan hasil penelitian menggunakan IPA, diketahui tingkat kesesuain dimensi kualitas kegunaan sebesar 96,55\%, dimensi kualitas informasi sebesar 95,55\%, dimensi kualitas interaksi layanan sebesar $96,06 \%$ dan dimensi kualitas antarmuka pengguna sebesar 96,77\%. Dari hasil tersebut, dapat disimpulkan bahwa dimensi yang paling besar nilai tingkat kesesuaiannya adalah dimensi kualitas antarmuka pengguna dan yang paling rendah adalah dimensi kualitas informasi. Dan hasil tingkat kesesuaian total sebesar 96,22\%, yang mengartikan bahwa pengguna kurang puas terhadap layanan E-Government. Hasil penghitungan tingkat kesenjangan (gap), diketahi gap dimensi kualitas kegunaan sebesar -0,12, dimensi kualitas informasi sebesar $-0,15$, dimensi kualitas interaksi layanan sebesar $-0,13$ dan dimensi kualitas antarmuka pengguna sebesar -0,11. Dari hasil tersebut, dapat disimpulkan bahwa dimensi yang paling besar nilai gap-nya adalah dimensi kualitas informasi, dan dimensi yang paling rendah nilai gapnya adalah dimensi kualitas antarmuka pengguna. Untuk nilai gap secara rata-rata adalah sebesar 0,12 , yang mengartikan bahwa pengguna kurang puas dalam menggunakan layanan website SIMSARPRAS, karena harapan lebih tinggi daripada kinerja website SIMSARPRAS.

\subsection{Klasifikasi Kualitas Website SIMSARPRAS}

Setelah analisis data selesai dilakukan, selanjutnya memasukkan hasil penelitian untuk diklasifikasikan terhadap kualitas website SIMSARPRAS. Gambar 6 menunjukkan klasifikasi kualitas website SIMSARPRAS pada penelitian ini.

Berdasarkan Gambar 6, hasil analisis menggunakan regresi linier berganda menunjukkan kualitas website simsarpras berkualitas "sedang" dan hasil analisis menggunakan importance performance analysis (IPA) menunjukkan kualitas website SIMSARPRAS berkualitas "baik".

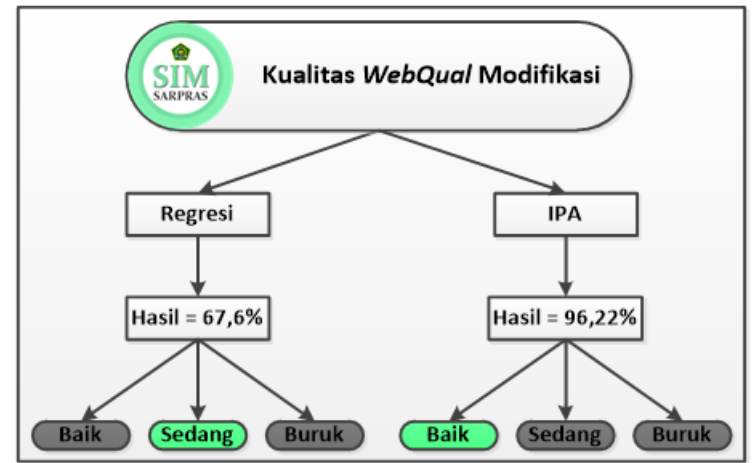

Gambar 6. Hasil klasifikasi website SIMSARPRAS

\section{KESIMPULAN}

Kesimpulan pada penelitian ini adalah dengan menggunakan regresi linier berganda, kualitas website SIMSARPRAS berada pada klasifikasi sedang, atau berkualitas sedang. Sedangkan dengan menggunakan importance performance analysis (IPA), kualitas website SIMSARPRAS berada pada klasifikasi baik, atau berkualitas baik.

Hasil analisis menggunakan regresi linier berganda, diketahui bahwa dimensi pada WebQual modifikasi mampu mempengaruhi kepuasan pengguna sebesar $67,6 \%$, dan $32,4 \%$ dipengaruhi oleh variabel lainnya.

Dengan menggunakan IPA, diperoleh nilai tingkat kesesuaian total sebesar 96,22\%, rata-rata nilai gap sebesar $-0,12$, yang mengartikan bahwa pengguna kurang puas dalam menggunakan layanan website SIMSARPRAS, karena harapan lebih tinggi daripada kinerja website SIMSARPRAS.

Saran untuk peneliti yang akan datang dengan studi kasus yang sama, penulis menyarankan melakukan penambahan variabel dalam penelitiannya, atau menggunakan metode yang berbeda, untuk mendapatkan hasil yang lebih lengkap dan detail.

\section{DAFTAR PUSTAKA}

ARIFIN, J., 2017. SPSS 24 untuk Penelitian dan Skripsi. 1st ed. Jakarta: PT Elex Media Komputindo.

BARNES, S.J. AND VIDGEN, R., 2003. Measuring web site quality improvements: A case study of the forum on strategic management knowledge exchange. Industrial Management and Data Systems, 103(5-6), pp.297-309.

CARUANA, A., 2002. Service loyalty The effects of service quality and the mediating role of customer satisfaction. European Journal of Marketing, 36(7/8), pp.811-828.

DAMANIK, M.P. AND PURWANINGSIH, E.H., 2017. E-Government And Its Application In Local Government. Jurnal Studi Komunikasi Dan Media, 21(2), pp.151164.

GHOZALI, I., 2016. Aplikasi Analisis Multivariete 
Dengan Program IBM SPSS 23. 8th ed. Semarang: Badan Penerbit Universitas Diponegoro.

GIYANTI, I. AND SUPARTI, E., 2018. Penilaian Kualitas Aplikasi Halal MUI dengan WebQual 4.0 dan Pengaruhnya terhadap Keputusan Penggunaan. Jurnal Teknik Industri, 13(2), pp.91-98.

HASAN, L., 2014. Evaluating the Usability of Educational Websites Based on Students' Preferences of Design Characteristics. International Arab Journal of eTechnology, 3(3), pp.179-193.

KEMENPERIN, 2018. Siaran Pers. [online] Available at: $<$ http://www.kemenperin.go.id/artikel/1896 7/Making-Indonesia-4.0:-Strategi-RI-

Masuki-Revolusi-Industri-Ke-4> [Accessed 9 Jan. 2019].

MADRASAH, S.D.S. DAN P., 2018. Buku Panduan SIMSARPRAS Untuk Madrasah. 1st ed. 2.0. [online] Jakarta. Available at: $<$ http://sarprasmadrasah.kemenag.go.id/sar $\operatorname{pras} />$.

NOVERIYANTO, B., NISA, L.C. AND BAHTIAR, A.S., 2018. E-Government Sebagai Layanan Komunikasi Pemerintah Kota Surabaya. Profetik Jurnal Komunikasi, 11(1), pp.37-53.

NUGRAHA, J.T., 2018. E-Government dan Pelayanan Publik (Studi Tentang Elemen Sukses Pengembangan E-Government Di Pemerintah Kabupaten Sleman). JURNAL KOMUNIKASI DAN KAJIAN MEDIA, 2(1), pp.32-42.

OLIVER, R.L., 1980. A Cognitive Model of the Antecedents and Consequences of Satisfaction Decisions. Journal of Marketing Research, 17(4), pp.460-469.

SANTOSO, B.S., ANWAR, M.F. AND HERMAWATI, S., 2015. Analisis Kualitas Website Menggunakan Metode WebQual Dan Importance - Performance Analysis (IPA) Pada Situs Kaskus. In: Conference: National Conference on Information Technology and Technical Engineering (CITEE).

SAPUTRA, R.A., SUPRAPTO AND RACHMADI, A., 2018. Penilaian Kualitas Layanan EGovernment Dengan Pendekatan Dimensi EGovqual dan Importance Performance Analysis (IPA) (Studi Kasus Pada Pemerintah Provinsi Nusa Tenggara Barat). Jurnal Pengembangan Teknologi Informasi dan Ilmu Komputer, 2(5), pp.1794-1802.

SETNEG, 2003. Instruksi Presiden Republik Indonesia Nomor 3 Tahun 2003 tentang Kebijakan dan Strategi Nasional
Pengembangan E-Government.

SETNEG, 2018. Peraturan Presiden Republik Indonesia Nomor 95 Tahun 2018 Tentang Sistem Pemerintahan Berbasis Elektronik.

SUTEJO, D., SOEDIJONO, B.W.A. AND SUNYOTO, A., 2018. Analisis Kualitas Website E-Government Menggunakan Metode Webqual Pada Pemerintah Daerah Morowali. Jurnal Informasi Interaktif, 3(1), pp.9-15.

ZEITHAML, V.A., BERRY, L.L. AND PARASURAMAN, A., 1996. The Behavioral Consequences of Service Quality. Journal of Marketing, 60(2), pp.31-46. 